\title{
New Production Systems in Transition: Implications for the Brazilian Industry
}

\author{
Novos sistemas de produção em transição: \\ implicações para a indústria brasileira
}

GUSTAVO ABEL CARRILLO GUZMÁN*

\begin{abstract}
RESUMO: Este artigo examina as mudanças que os sistemas de produção sueco, alemão e japonês estão atualmente realizando. Argumenta que as novas condições contextuais econômicas e socioinstitucionais em todo o mundo, juntamente com os eventos domésticos, estão influenciando as mudanças aos poucos no coração dos sistemas de produção sueco, alemão e japonês. Implicações para a indústria brasileira são discutidas.

PALAVRAS-CHAVE: Mudança estrutural; globalização; sistemas produtivos.
\end{abstract}

ABSTRAC: This paper examines changes that the Swedish, German and Japanese production systems are currently undertaking. It argues that new economic and socio-institutional contextual conditions worldwide together with domestic events are influencing a piece- meal changes at the heart of the Swedish, German and Japanese production Systems. Implications for Brazilian industry are discussed.

KEYWORDS: Structural change; globalization; production systems.

JEL Classification: P12; O10.

\section{INTRODUCTION}

The search for systemic competitiveness involves, among other factors, the careful choice, adaptation and development of a production system. While in the middle of the globalization process, Brazil continues searching for a model of production. The choice and development of a production model is a key factor that need to be addressed in order to contribute to overcome the structural fragility of Brazilian industrial competitiveness (Coutinho, 1997). This paper examines changes that three paradigmatic production systems (the Swedish, the German and the Japanese) are currently undertaking. It contributes on the debate and understanding

\footnotetext{
* Departamento de Engenharia de Produção da Universidade Federal de Minas Gerais - UFMG, Belo Horizonte/MG, Brasil. E-mail: gguzman@dep.ufmg.br.
} 
of the dynamics of production systems. This is important since Brazilian firms usually undertake a mechanical adoption or narrow adaptation of new production concepts, such as the Japanese 'Lean' model, without considering recent trends in the industrial world, resulting in limited positive outcomes (Meyer-Stamer, 1997). In the next section key features of productions systems are outlined. These arguments will inform the discussion on two developments that might result in the amalgamation of Japanese, Swedish and German production systems. Firstly, the trend towards 'Japanization' of Swedish and German prodution systems (section 3) and; secondly, the trend towards 'Europeanization' of the Japanese production system (section 4). The possible hybridisation process, the theme of section 5, helps to throw some light on the likely paths of hybrid forms of new production systems (NPS). Finally, section 6 concludes raising key implications for the Brazilian industry.

Before proceeding to comment on those insights, it is necessary to rnention common agreements in the literature concerning (Durand, 1993; Altmann et. al., 1992; Boyer, 1993): (i) the recognition of the existence of an ongoing process of industrial restructuring in developed economies in terms of management of production and new ways of competition linked to specific sectors such as the machine tool and automobile industry where a high density of new technology exits; (ii) the present erosion of work, organisational and institutional structures deployed along tayloristic lines, does not mean that it has already been replaced by other approaches (e.g., taylorist/fordist views, in general terms, continue to be the dominant approach even though it seems that they are undergoing a gradual transformation in the advanced economies' high technology sectors). Little agreement exists among observers regarding the quality, significance and extent of the restructuring process. However, commentators agree on the decisive influence of particular socio-institutional features each nation possesses to support or constrain industrial restructure (Lutz, 1992: 32-7).

\section{ON PRODUCTION SYSTEMS 1}

Production systems are approached in this paper frorn a broad view. Both micro level developments (e.g., technology strategy, work organisation, managernent, human resource and industrial relations practices) and its associated macro contextual conditions (e.g., labour markets, product demand rate and level of economic activity) in which production systems are inserted, constitute their two key dimensions. Next, key features of a production system, that transcend specific characteristic of each model, are explained. In doing this the following arguments are advanced. (1) micro and macro dimensions of a production systems are highly interdependent; (2) all production systems are intrinsically different; (3) achieved

\footnotetext{
${ }^{1}$ This section is based on insights from a comparative examination of Swedish, German and Japanese Production systems. For details see Guzman (1998).
} 
working conditions and living standards are function of the degree of workers input in both production and distribution issues; and (4) production systems are dynamically evolving.

Micro and macro dimensions of a production systems are highly interdependent: all production systems are constituted by two highly interdependent dimensions: the micro and the macro. The failure to consider simultaneously both dimensions results in a partial picture of the problem, as the sustained functioning of micro level features seems to be highly dependem on the macro contextual conditions. From the acknowledgement that different models follow different strategies and pursue different goals, it can be drawn that a condition that seems to be crucial, for the development and diffusion of a production model, is the congruence that exists between firm and macro level factors. Key explanatory arguments for the model's differences and similarities nevertheless, resides in the macro dimension. Japanese production practices and principles, for example, were able to be implemented because they helped to achieve the government and firm goals of economic development on the one hand, and helped to raise standards of living of the general population, within the resource limitations that Japan had. Important macro pre-requisites that contributed to the development of the Japanese production system were the minimalist State Welfare system; the strong government support for key industries developing export capacity (e.g., Japan's Ministry of international trade MITI); the weak TU bargaining power to raise claims and the existence of a trained and educated workforce. This situation leaves Japanese worker with little alternative but to accept Japanese production concepts, independent of consequences for workers. In the case of Sweden, sociotechnical principles worked well as they reflected prevailing democratic traditions, helped to solve high labour instability (high turnover and absenteeism rates), improved working conditions and sustained industrial production. Crucial macro pre-requisites, such as the existence of active labour market policies to acquire further skills, a wage solidarity policy, a labour oriented government and the existence of strong and organised TUs, constitute key contextual factors that further explain the Swedish model (Sandberg et. al., 1992). In Germany, their particular production principles evolved as a consequence of the prevailing 'co-operative' corporate policy, the economies of scope orientation, the existence of a pool of highly skilled workers, the efficient training mechanisms and the co-determination laws that allowed worker's input for obtaining industrial efficiency.

All production systems are intrinsically different: Despite some common characteristics that these models have, it is necessary to remark that to a in certain extent, each production system is unique as it evolved responding to specific time, space and societal needs and consequently built particular capabilities to cope with their macro contextual conditions. Thus, paraphrasing Cole (1990), is necessary to admit that there is inevitably an element of comparing apples with oranges. A comparative examination is useful as it helps to explain the functioning of each model within a wider macro picture. However, rather than try to determine which production system is superior, the important question should be under what condi- 
tions and in what environments different production systems perform effectively considering the outcomes for both the firm, personnel and society at large (see next section). To sustain the argument that all production systems are intrinsically different, two key issues are focused on, the different strategies followed, from conception, within each production system and; the wider long-term goals of firms and government policies which permeated the development of each production system. Different production system, different firm level strategies: Japanese corporations opted for an outward expansion strategy to secure long term survival. With the intention of serving overseas markets Japanese firms concentrated sharply on the mass-production of high quality and low price products and have developed the ability of reacting rapidly to customers' needs. German industries have focussed attention on few industrial sectors to develop economies of scope and technical excellence. They have developed the capacity to produce high performance and quality products either for mass markets or for special customers (customised products). Swedish firms like the Japanese, followed an export-oriented strategy, but opted for targeting the production of technically sophisticated products, competing in high quality and sophisticated design stances. This means manufacturing in small/ medium-sized batches for niche and luxury markets. The above suggests that different production models therefore seem to be more adequate in serving specific markets than others. While both the German and Swedish models seem to be adequate for producing high performance customised goods (usually capital goods) for high quality markets in either relatively high volumes (Germany) or small/medium volumes (Sweden), the Japanese model is efficient for the mass production of high quality and low price consumer goods (Appelbaum and Batt, 1994).

Long-term goals of firms and government policies: The efficient production of manufactured goods is an apparent similar goal of all production systems as 'efficient' production does not only have different meanings in different settings but also different forms exist to achieve it. For example, while Japanese firms seek to increase the level of productivity as a means of obtaining economic growth and therefore long term economic stability (leaving aside firm level 'distribution' issues), the Swedish system approached firm level productivity as part of a wider system to achieve a higher standard of living for the general population under an egalitarian approach.

Achieved working conditions and living standards are a function of the degree of workers' input in both production and distribution issues: A crucial difference between the Swedish, German and Japanese models is related to the extent to which Labour can influence 'distribution' (ie, matters related to rewards and profit distribution) and 'production' (e.g., matters related to work organisation and technology usage) issues. Empirical evidence (Bowles and Gintis, 1995) has suggested a significant liaison between degree of labour input in production and distribution issues and both working conditions and the general living standard exists. The more the labour input in production and distribution issues the better the working conditions and the higher the general living standards. Considering the degree of worker input in both production and distribution issues, it is possible to distinguish two 
groups. On the one hand, the Japanese production system, in which labour has a small input in both production and distribution issues when compared to Swedish and German cases, seems to have lower level of both working conditions and living standards than the Swedish or German cases. In Sweden and Germany workers have high input in both distribution and production issues. In Germany codetermination laws which support worker input in workplace related decision-making (production issues) seems to be more developed than existing mechanisms to favour worker input in distribution issues. Conversely, Swedish codetermination laws promote more worker input in distribution issues than in production issues. The rough outline of production and distribution issues in the three cases, together with the micro/macro view sustained, leads us to suggests that (i) as both production and distribution issues seem to be key for the improvement of both working conditions and living standards, industrial relations factors are crucial for defining the performance of the production system; (ii) firm level production organisational features, that are relatively easy to replicate, constitute only a fraction of a production system and neither reflect the complexity of the process of adaptation nor its consequences over the whole society. The above points suggest that the political-economy examination of the production systems seems to be the appropriate level of analysis because it incorporates in the analysis not only cost and benefits but also distinguishes key social actors and their power holding position. In other words, any examination of production models ought to consider three essential questions. Firstly, how are gains and lasses distributed? (e.g., under what rationale 'gain' and 'loss' are defined by different social actors); secondly and more importantly, who decides who gains and who losses? thirdly, under what contextual conditions are worker input on both production and distribution issues more likely to be developed?

While some answers for the first two questions have been outlined above, any answer for the third question might seem premature as NPS are still in their formative stages. Nevertheless, based on comparative studies Turner and Auer (1992: 4-5) have advanced four hypothesis which illustrate possible development of new hybrid models and their relation to macro institutional factors:

Where Unions are integrated in management decision-making processes through entrenched legal or bargained institutions of codetermination, unions in the current period of work reorganisation will develop proactive strategies to influence the shape of new organisation. The result will be negotiated solutions: new shopfloor organisation will take shape in a bargaining process between labour and management. One can expect in these cases that while some aspects of lean production will be adopted for efficiency purposes, other human-centred concerns that are not part of the lean system (such as longer cycle times, more autonomy for work groups, and elected group leaders) will also be incorporated. This pattern can be seen in Sweden as is developing in Germany.

Where unions have long established arm's-length relations with employers and no formal rights in management decision-making, unions 
will face a choice between collaboration and opposition but will be unable to play a proactive role in influencing the shape of new work organisation (at least until the arm's-length relation is substantially changed). Management will push for the implementation of its own team's concepts (heavily influenced by Japanese/lean models). The transition to new work organisation will be rocky as management encounters a patchwork pattern of acceptance and rejection within the workforce, as the US experience indicates.

The specific form and implementation of new work organisation is linked not only to industrial relations but to other factors such as national and local labour market conditions. The drive to implement human-centred forms of work organisation is stronger in tight labour markets, where competition for labour is based not only on wages but on the quality of jobs. In loose, low-skilled labour markets, new forms of work organisation are less necessary to attract labour, leaving roam either for lower skilled, traditional work organisation or for lean production.

There is a link between labour-market incentives for work reorganisation and the national (and local) vocational training system. If such a system produces high skills as a ' public good', the spread of human-centred work organisation based on high skills content becomes more probable. Contemporary Swedish and German experience provide evidence for this claim.

Production systems are evolving dynamically: Because macro contextual conditions are continually changing the firm level bundle of features is also, formally or informally, slowly or rapidly, evolving to be congruent with current macro conditions. The case of Sweden is representative. Because the newly liberal-oriented government set up (questionable) economic policies for improving industrial performance (eg, $20 \%$ devaluation of the currency), indirectly allowed decentralised negotiations between firms and TUs and scrapped the full employment policy, some key features of the Swedish production model no longer can stand. For example, wage solidarity policies are difficult to implement as outcomes of local negotiations are highly heterogeneous; the promotion of active internal labour markets is limited by the lower investment that firms do for (re)training their own personnel as existing unemployment allow personnel to be hired straight from the labour market (Berggren, 1994; Meidner, 1994; 1997). In the case of Japan contextual conditions of the 1990s are also pressing the adaptation of some 'pillars' of the Japanese model. In the automobile industry for example, the rise in the education level of young workers allied to their awareness of working conditions in other nations, make it difficult for firms to hire young skilled personnel. With the Japanese economy in recession, the stagnation of firms' market share hinders the implementation of active internal labour markets as well as undermining some key institutions that helped to build worker commitment and loyalty to the firm: seniority wages, group 
performance evaluation and external JIT, for example, are starting to be limited in order to enable the 'economic survival' of the firm (Berggren, 1995; Benders, 1996). In Germany, the Japanese 'threat' together European market unification and large investments needed by former East Germany to catch up competitiveness, are pushing Germany to rethink its production model. It has become imperative to catch up with Japanese productivity levels. Therefore, within the codetermination frame, Japanese style organisational innovations have been started to be implemented. Different forms of Japanese style workgroup, selected JIT and Kaizen techniques are being tried. The cost-target approach for example is being introduced to overcome problems emerged by over-engineered practices; the use of simultaneous engineering and the creation of Japanese type network of suppliers, accompanied by vertical de-integration; and a diverse mechanism to increase workers' accountability for outcomes are already being implemented (Jurgens, 1993a). A brief outline on how these new developments towards hybrid forms of NPSs are being deployed is outlined in the next sections.

\section{TOWARDS THE JAPANIZATION OF SWEDISH AND GERMAN PRODUCTION SYSTEMS?}

White there is increasing evidence that Swedish and German companies are applying Japanese type production practices and concepts, there is not a clear picture on how this process occurs and which are the associated problems that this move might bring. Next, latest developments are reviewed.

The adaptation of Japanese concepts by Swedish and German firms: Empirical research (Kumazawa, 1992; Cook, 1993; Enderle, 1997) has suggested that a wide spectrum of different production practices have been occurring, as a result of piecemeal borrowing from different models. Techniques and concepts are differently adapted in different work situations; as different firms possess different availability of skilled workers, both workers and TUs react differently; external labour markets are different in different regions and nations, so the pressure for workers to accept Japanese type working conditions is different. On the one hand, the Mercedes Benz's plant in Rastatt for example, Swedish Uddevalla concepts were blended with German production concepts supplemented by a touch of Japanese Kaizen practices. Then, the traditional assembly line was abolished in around half the operations and there is a universal attempt to achieve integral, long-cyclic work content (work content of 1-2 hours in stationary areas and 15-45 minutes on the assembly line). On the other hand, the 'Japanisation' of German plants is occurring but in peripheral sites only, in which codetermination laws do not apply or are just beginning to be implemented. That is in both former East German sites and overseas. To operate this strategy, different approaches are followed. For example, a joint venture with Toyota for the production of vans in its Hanover plant; changes towards the implementation of JIT and Kaizen techniques in its engine plant at Salzgitter; new Japanese type work practices at Martorrel and Mosel (in the former 
East Germany) and the total 'japanisation' of GM Europe's Eisenach plant ${ }^{2}$ (Jur gens, 1992, 1993a, Auer, 1994). The heterog enous trend for adaptingJapanese type work and manage ment strategies in Germany brings massive problems.

Problems of adopting Japanese concepts in German and Swedish firms: At the level of the firm, the following problematic issues are emerging (Auer, 1994; Kumazawa, 1992; Cook, 1993): (i) White management has clear goals in adopting Japanese techniques (e.g., to achieve efficient production), workers and TUs have to develop strategies in such a way as to not lost acquired rights (e.g., paid vacations, limited working hours, overtime payment, sick leave and so forth); (ii) because the Lean concept is vague, many 'Japanese' concepts can be vested as 'European' because of their similarity: multiskilling, group work and some kaizen techniques can be part of both models; (iii) the German institution of skilled (semi) autonomous workers, is not compatible with some Japanese practices. For example, Japanese on-the-job training programs for multiskills departs from the German 'humanisation' of work policies and vocational training mechanisms: "in fact, the so called 'multiskilled' versality required of an employee is frequently no more than an adaptive capability to perform a number of simplified operations as swiftly as possible in a limited amount of time" (Kumazawa, 1992: 111); (iv) employee participation (input) in decision-making exists but it is harnessed to promote further elimination of waste and defects (only); because no 'idle time' is allowed to workers and relief workers do not exists, work intensity is high; (v) the existence of independent TUs and codetermination laws is highly incongruent with the Japanese model as it does not enable management unilateral decisions in labour deployment and work organisation (e.g., work load, job definition, manning level, and transfer of workers) as well as in setting the rules to define the variable component (based on individual performance evaluation) of wage; (vi) A similar picture occurs in small and medium firms. As a result of outsourcing policies, small and medium firms would eventually have raising demand, but this will occur only if they comply with the costcutting and quality standards of customers. Additionally, as risk-sharing and fair payment policies are not yet developed, the actual relationship between large and sub contracted firms are more like master-slave relationships than partnerships. ${ }^{3}$

At macro institutional level, because significant institucional and socio-cultural differences exists between German and Japanese Industrial relations systems, the application of Japanese type practices either by German firms or by Japanese companies in Germany, is not expected to be without problems. The following problems

\footnotetext{
${ }^{2}$ At the Eisenach plant, NUMMI and CAMI were models for the design of the plant. So, the Japanese type team principles were widespread; the assembly line was conventional; cycle-time were short and the kanban system was introduced. The workforce however, seems to have higher qualifications that of Japanese plants in Japan and in USA as all them possess the Facharbeiter training (Jurgens, 1993a).

${ }^{3}$ Berggren (1992) has pointed out similar findings at US transplants: no regulation of work intensity; excessive demands for overtime work, intense pace and repetitiveness; long working hours leading to significant health problems; and stringent factory regulation (e.g., mandatory uniforms, exacting attendance demands, detailed codes of conduct and discipline, elimination of all personal attributes).
} 
have been raised (Deutschman, 1992; Nomura, 1992; Sauer, 1993): (i) the set up of a 'competitive' (Japanese style) network of suppliers in Germany involves ambiguous consequences: A falling number of first-tier suppliers, establishing a hierarchically organised pyramid, job cuts in parent firms as whole components can be designed/manufactured by suppliers; further skill polarisation in suppliers; and stress caused by high workload, close deadlines and flexible adjustment to needs of customers, changed status of employment (towards low-waged fix-term and temporary employment); and changed structure of working time (e.g., more shift work and overtime) on the one hand. On the other hand, as parents firms reduce their in-house design and/or production activities, the level and status of employees is stabilised; as demand might eventually increase, the expansion of capacity contributed to growth; the realisation of more design and manufacturing activities, with its associated quality assurance and logistic areas, might lead to the further acquisition of skills; (ii) the existence of closed internal labour is basic pre-condition to developing and applying (Japanese style) complex appraisal and wage systems, useful for 'managing employees individually and thoroughly'. Again, closed internal labour markets are not common practice in Germany; (iii) the Japanese model assumes the existence of an employment security mechanism that works as trade off for workers' acceptance of internal adjustment, industrial peace and identification with corporate strategies and employment. Nevertheless, this mechanism seems to be suitable for the Japanese context in which low unemployment levels occur and the employment stability of the whole system is based on the low employment stability of subcotracted firms. It follows that for Western firms to successfully adopt Japanese style concepts employment security mechanism does need to exit. How will those be developed in nations, in which two digit unemployment level occurs and the unemployed are, usually, part of long established Welfare State mechanism?; (iv) an important critique to the implementation of the Japanese model in western settings is that it challenges the whole economic system in which Western firms evolved (Auer, 1994). Because Japanese production involves 'lean' workforce (e.g., less number of workers per produced unit) there seem to be an embedded component which favour further unemploymem levels. This becomes a structural problem when Japanese production rationalisation practices are applied in all economic sectors and are combined with job saving new technology and job cutting reengineering concepts. ${ }^{4}$ While it can be argued that this is not the only time unemployment has occured (e.g., the case of the introduction of new technologies), this time special conditions seem to exist that raise worrisome questions concerning not only the future of work but of the whole economic system, as less full time well

\footnotetext{
${ }^{4} \mathrm{~A}$ McKinsey report forecast that 'the removal of trade barriers can be expected to lead to millions of pounds' worth of lost sales for European motor manufacturers, accompanied by the loss of more than 100,000 jobs, as a result of the inflow of Japanese products and capital' (Newmann, 1993). Jurgens (1993a) has also pointed out that VW and Mercedes-Benz, for example, have already reduced their personnel by around $15 \%$ within the framework of introduction of 'Lean' production concepts.
} 
paid workers means market reduction and less taxes to support the increasingly larger Welfare State system.

In summary, because above developments are still occurring, there is no clear answer to those questions. What is clear however, is the view that the resolution of the above challenges is a function of the general state of industrial relations at macro level. That is, while managemem choice is important, the sustainable implementation of Japanese type techniques seems to be closely linked to TUs bargaining power (to minimise potential negative outcomes) and government policy trends (roughly, either pro labour or pro liberal types). In Germany for example strong TUs, codetermination laws are favouring not only a slow imroduction of Japanese production techniques but also their 'adaptation' to German conditions. German TUs have proposed a 'productivity pact' supporting the introduction of Japanese production techniques in exchange for expanding the co-determination rights to personnel staffing levels and thus performance standards in the white collar area (Jurgens, 1993a). Nevertheless, while Government, industrialists and TUs are discussing these problematic issues, the emerging picture, from a labour perspective, reveals a dark view since there seems to be an increasing work intensity and the declining volume of jobs.

\section{TOWARDS THE EUROPEANIZATION OF JAPANESE PRODUCTION SYSTEM?}

Because of different reasons, the Japanese production system seems to be changing too. Japan's growing surplus of in foreign trade, domestic socio-economic problems, increased awareness of the youth and general population regarding the use of free time for leisure and its associated labour shortage implications, declining profits together with international pressure to have access to the protected Japanese domestic market are calling for the structural adaptation of the Japanese economy. This seems to constitute a key pre-requirement for Japan being entitled to have access to a large market (e.g., NAFTA and EC agreements) (Demes, 1992; Nomura, 1992b). Key social actors (industrialist, TUs, and government) have already started to implement new policies to adapt both production issues (e.g., policies aiming for better working conditions) and distribution issues (aiming for the improvement of job conditions such as shorter working hours, longer holidays, better wages) to the new contextual conditions.

Several cases of the application of Swedish style production organisation concepts have already been registered in Japan, both in mass and non-mass production (Gronning, 1995; Shimizu, 1995). At Toyota for example, the concept of 'autonomous Complete Process', was implemented. It involved the diminution of fragmentation of tasks to partially recover the contextual meaning in assembly, but without eliminating the assembly line. In Toyota's new Tahara plant for example, work organisation and layout were designed to reduce the intensity of work, to remove workers partially from the line and to establish better working conditions (Japan Times quoted 
by Newmann, 1993). Instead of the traditional assembly line, 8 mini lines with 5 -minute buffers were set up in order to make each section, as far as possible, selfcompleting. At Toyota's Kyushu plant, besides the similarity that the assembly shop has with Swedish Kalmar concepts, the main innovations were introduced in the reward system, working hours, management style and suggestion schemes. At Kyushu, there was a 'continuous shift' system (e.g., first shift 06:00-14:50 and second shift 15:05-23:55) implemented in order to minimise forced overtime; the new suggestion system was not interested in the number of suggestions per worker per year; there were not targets; the assembly line was divided in 11 minilines with 5 -car buffers at each mini-line; each line was the responsibility of a production team. In the Honda plant at Takanezawa and the Daihatsu plant in Osaka, Uddevalla type work organisation was applied: assembly work without assembly lines in which skilled workers work with long cycle times and have a wide range of deployment possibilities. In other assembly industries such as video camera, photocopy machines, portable telephone, air conditioner and so on, assembly work with a team and without belt conveyer have now been introduced (Berggren, 1995: 76-8; Nohara, 1997). It should be noted that above Swedish style organisational innovations are in total discrepancy with some of the central Ohno 's principles: as buffers are introduced and work partially is decoupled from the line (using mini-line concepts), a lesser degree of interdependence between production tasks occurs. Those deployments call for new forms of production and worker controlas Kanban and JIT techniques are more suitable for highly inter-dependent tasks than for decoupled tasks. Therefore, it is expected Japanese managerial style would also evolve.

Government policies aiming to increase employees' share in national wealth in order to improve living conditions have already been outlined. The 1992 'The 5-year Economic Plan: Sharing a better Quality of life Around the Globe' plan was published by the Japanese government. This plan proposed reducing working hours in the long term; increase the minimum overtime wages; set up of new shift models to reduce required overtime including non-paid overtime; reduce the school week to 5 days; enlarging the cycle of some products (especially electronics) as this is linked with increasing demand for overtime work and is raising criticisms as it supports the 'wasteful' society trend (Demes, 1992; Nomura, 1992b).

A further step occurred in May of 1995, when the Japan Federation of Employers' Association (Nikkeiren) proposed a new type of Japanese management in the document 'Japanese Management in the New Era - its orientation to be challenged and its measures' (Koyama, 1997). The Nikkeiren document explicitly points out that the traditional 'three pillars' of Japanese management (e.g., lifetime employment, seniority-based wages and the co-operative relations between labour and management) will radically change. The final goal of Nikkeiren seems to be the improvement of competitiveness through the flexibilization of employment and Human resource policies. The framework for the flexibilization of employment 
relations involves the classification of employees in three groups, each group would be employed under different contractual conditions. The first group called 'long term accumulated ability' have similar job and working conditions as in the former 3 -pillar system. That is personnel is employed on a permanent basis and embraces managers, executives and technical staff; wages are based on the evaluation of individual job-ability accompanied by fixed rate and scale bonuses; promotions are based on job classifications and the retirement allowance and pension system is based on a points system. The second group, 'higher professional ability group', is directed to regulate job and employment conditions of special department staff (e.g., $\mathrm{R} \& \mathrm{D}$, planning, sales); fix term employment contract; wages, bonus and promotions are a function of results achieved; there is no retirement allowance or pension system. The key departure from the traditional Japanese model, for these two first groups was the introduction of some type of 'time autonomy' for white-collar workers and non-routine jobs as a counter-part measure for the new results-oriented wage and promotion systems. The third group is directed to regulate employment and job conditions of the peripheral workforce. That is, personnel performing general duties, some technical and selling jobs are contracted under fixed time periods; wages are defined by time rates and job evaluation; bonuses are fixed and neither a retirement allowance nor pensions nor promotions exist.

The above policy recommendations represent an importam shift (or evolution) in the constitution of the Japanese model. The results-oriented wage system, the 'time autonomy' idea and the flexibilization of employment relations points out a convergence of employment and wage relations with the Western approach. While it seems to be clear that the traditional '3-pillars' of the Japanese model are being scrapped, it is not clear which are the implications for both workers and firms. On the one hand, the flexibilization of employment conditions without doubt will allow firms leeway to deal with market fluctuations as the third group of the Nikkeiren document represents the legalisation of illegal employment (foreign, women and older workers) and its associated lower wage, job and working conditions. On the other hand, it is still too early to evaluate if those new measures will allow the firm to have highly motivated skilled personnel 'on call', as the institution of internal labour markets will be relaxed and external labour markets are not enterprise controlled.

The 'new' system involves, for workers, a trend towards the personalisation of wage relations, further job intensity (for groups and individuais), the further polarisation and instability of employment and increase of competition among employees (for groups 2 and 3)..$^{5}$ This means (i) the formalisation of less egalitarian policies (as the 3 groups have different working and job conditions); (ii) the legalisation and

\footnotetext{
${ }^{5}$ Individual assessment that increases competition among groups brings new problems for maintaining 'family atmosphere' that Toyota pursues and that helps to create corporate culture, a basic element of the Japanese system. This involves the pursuit of a large number of 'human relations' activities which occur off-duty. Despite those human relations activities not being compulsory, 'employees think that personnel assessment will go down when he refuses to participate in the activities. Because of these activities supervisors and managers hardly have private time on holidays' (Nomura, 1992b: 15).
} 
perpetuation of lower working and job conditions for the peripheral workforce (group 3 ); (iii) the 'flexibility' of external labour markets will promote high work instability for highly skilled personnel (group 2). In short, the Nikkeiren approach for adapting the Japanese model to new contextual conditions, seems to represent, in the name of economic goals, a step backward in work and job conditions, which in societal terms means higher social unequally. While the above direction seems to converge with Western style industrial relations, it should be noted that state welfare mechanisms in Western nations are fairly well developed (minimum living standards are assured to workers), something that does not occurs in Japan. In spite of the controversy that the above development may generate, Jurgens (1993a) argued that the key question is whether or not the new type of Japanese wage and employment conditions will be able to sustain workers' loyalty, morale and consent on the one hand, and on the other hand, to what extent the new Japanese model will be able to adapt European Humanisation of work approaches to simultaneously make work attractive, sustain increasing factory automation, and provide intensive training for automated equipment maintenance areas. The answer seems to be function of the capacity of the new system to deliver improved working and job conditions.

The (representative) automobile industry for example, is already implementing measures aiming for both the improvement of working conditions and the implementation of the above mentioned new job and employment conditions. For example, Mazda in Hofu, Nissan and Toyota in Kyushu new plants are introducing measures and concepts directly linked to the improvement of working conditions; ergonomic aspects for example are being considered for the first time, noise reduction devises, longer cycle times, introduction of buffers and storage units as well as the improvement of canteens and sports facilities are some common measures introduced (Demes, 1992). At Toyota, the concept of 'necessary' waste to improve human conditions is being introduced (Nomura, 1992b) and this involves the use of buffer stocks and the review of the JIT delivery system, one of the 'pillars' of the Japanese model. Together with those changes, Toyota has started to change its wage system and new employment practices (eg, the concepts of age and skill related payment were introduced and the proportion of productivity wage was reduced from $60 \%$ to $40 \%$ ) since early 1990 (Koyama, 1997). Therefore, it does not seems to be a coincidence that those improvements are very similar to those discussed and implemented in Sweden and Germany in the 1980s under the 'Humanisation of work' program, as the labour market problem that Japan is facing in the mid 1990s is similar to the Swedish and German situation in the 1980s. While those changes in the Japanese model seem to depart from traditional Japanese concepts, they, as Benders (1996) noted, look like more evolutionary than revolutionary.

\section{POST-LEAN PRODUCTION: JAPANESE PRODUCTION ORGANISATION CONCEPTS WITH “HUMANISATION OF WORK” SPIRIT?}

So far, it was suggested that both the Japanese and European (Swedish and German) production systems are, as presented today, unable to cope with macro 
contextual conditions. Then the argument developed here is that a synthesis of both models is being shaped by key social actors. The new synthesis would involve the adaptation of some Japanese production organisation techniques that match advanced European industrial relations practices. This process seems to be, from the rational perspective, adequate as Swedish and German contributions in work organisation and job design have occurred in areas in which Japanese management did not focus. This wave of change paradoxically has an European 'Humanisation of work' flavour. While it is too early to evaluate how this process is being developed, in this section, a possible hybridisation or new synthesis of Japanese and European model is outlined.

There are features in both models which can be amalgamated and features in which combination is difficult due to the contradictory characteristics of the concepts involved (Berggren, 1992). On the one hand, elements of the two models which are feasible for combination are: (i) the use of Japanese product development concepts and techniques (e.g., QFD) would greatly improve the Swedish design process; (ii) the use of Japanese type relations with suppliers; (iii) the adaptation of some elements of Japanese standardisation of procedures to the long-cycle Swedish way of work, would benefit the latter by creating order and a more systematic approach to developing standards for critical tasks as well as improved tool and QC procedures for example.

On the other hand there are 2 features in each model which seems to be difficult to fit. Firstly, the current Japanese approach to waste, that involves low buffers among units and results in high task interdependence. The recognition of the need for 'socially' acceptable waste, as suggested by Nomura (19926), will make it feasible to adapt some Swedish or German work organisation principies, which are based on the de-coupling of workers from the production line in order to provide leeway for problem-solving activities. Secondly, there is a central contradiction in both production systems which is based on the concept of flexibility. Flexibility can be approached (as the Japanese model does) just in pure economic terms, demanding employees achieve numerical goals; or flexibility can be approached considering both economic outcomes and human needs.

Features of the Swedish model that might help to improve the Japanese model are (Berggren, 1992: 252-4):

- The integration of subdivided tasks and monotonous mass-production work to more dignified and holistic tasks. Swedish experience showed that there are tech nically feasible alternatives, compatible with varied market demands and socially sound outcomes;

- The broad development of the physical work environment, especially the ergonomic aspects of manual workplaces in order to minimise repetitive strain in Jury;

- The efforts to make work systems less rigidly coupled and more adaptable to meeting diverse human needs; 
- The high degree of involvement of Unions in decision making and planning processes as independent partners with legitimate interest on their own.

Thus, it is possible to suggests that, at the firm level, the main point of combining features from the two models lays in aspects related to work organisation and production design. Nevertheless, because different plants possess different degrees of automation, work organisation patterns, management styles background, serve to different markets, and are inserted into different contextual conditions, a wide variety of hybrid models are feasible to emerge. Fujimoto et. al. (1997) have interpreted those developments as a simultaneous process of convergence and mutual learning at the level of techniques, management practices and organisational forms. Convergence regarding the spread of specific JIT techniques such as teamwork, problem-solving activities and product based layouts. Mutual learning occurs as a result of the process of borrowing among the main production systems. Nevertheless, should be clear that while some convergence of rationalisation is occurring, there is a divergence on interest representation and wider industrial relations (Altmann, 1992).

Because there seems to be a transitional time, preliminary conclusions can be drawn only. Firstly, it can be suggested that more than the 'survival' of one specific production system, the late 1990s is witnessing an 'evolutionary hybridisation' process. In this process different firms (usually automobile producers) borrow particular concepts from different production systems in a piece-meal fashion. This process nevertheless, seems to be strongly constrained by national macro contextual conditions such as labour and product markets, the wider industrial relations system, quality of available manpower skills and level of economic activity, among others. ${ }^{6}$ Second, the wide diversity of resulting hybrid models would be complementary since one firm usually posses different plants serving different markets and so they might have different production design orientations.

The above developments bring massive implications for Brazilian industry because simultaneous endogenous and exogenous macro institutional transformations have been occurring since the early 1990s. In the next section preliminary implications are outlined.

\section{NEW PRODUCTION SYSTEMS IN TRANSITION: IMPLICATIONS FOR BRAZILIAN INDUSTRY}

So far, available evidence has pointed out what can be qualified as an evolutionary transformation of the Swedish, German and Japanese production systems. This is crucial for any nation looking for boosting industrial competitiveness since

\footnotetext{
${ }^{6}$ Empirical evidence on how this process is occurring in assembly operations can be found in Shimokawa, Jurgens, Fujimoto (1997).
} 
those production systems have a role of model. In what follows 5 implications for Brazilian industry are suggested.

Firstly, while the production system is the mean to achieve industrial competitiveness, it is not the only one. Further, the production system functioning depends on other no less important stances: (a) Degree of development of institutional factors such as labour markets; trade unions effectiveness; Labour laws; and training institutions. (b) Political trajectory in which the production system is inserted (e.g., from neo-liberal oriented to Keynesianism). (c) General state of the nation's economics. From those items, the first seems to be crucial (Meyer-Stamer, 1997; Tauille, 1994) since it implies the set up of new patterns of governance, such as changes in the electoral and tax systems as well as the redefinition of roles for key social actors (e.g., business associations, workers associations, public sector).

Secondly, the evolutionary hybridisation process that seems to be occurring between the Swedish, German and Japanese production system does not implies that firm level choices are between one model or another. Rather, empirical evidence (Shimokawa et. al., 1997; Guzman, 1998a) suggested that it is possible to implement different types of restructuring at the same time at different organisational levels. Different production concepts can be totally or partially adopted and can even be adapted to local conditions in a wide range of forms. In other words, operational concepts and techniques can be applied selectively in particular areas or at the firm wide level. Each dimension of the chosen model can, in turn, be implemented in a wide range of forms and to different degrees. As different firms possess both different operational 'needs' and market targets and as well as are located in particular regions with particular labour market features, they might apply different models to different extents. So, an important question is not which model is superior, but how firms are selectively applying different principles at different organisational levels and, which mix of macro contextual conditions support or constraint the adaptation of new production concepts.

This also raise a key issue for the organisation of production at the level of the firm: How to make sense different manufacturing policies since different production systems calls for different managerial control structures, authority practices, technology deployments, work organisation and human resource management practices? At macro level, it is far from clear how, why and to what extent different production systems combinations are competitive and feasible to implement and its implications for both management and labour. This might become a key issue in any research agenda focusing on modern manufacturing systems.

Third, despite the importance of firm level strategic choice, macro institutional conditions seems to play a persuasive role to select the production model(s) to be applied. ${ }^{7}$ The economic path taken by Brazil since early industrialisation, together with substantial changes in both industry policy and developmental

\footnotetext{
${ }^{7}$ A comparative examination between American and Japanese car industries (Williams et. al. 1995) have sharply argued that 'management actions may be relevant to competition within national
} 
orientation (c.f. Suzigan, 1996), have resulted in a general macro contextual industrial setting which, in some aspects, support the adaptation of NPS at firm level and in other aspects constrains NPS implementation (Coutinho e Ferraz, 1994; Fritsch e Franco, 1991). Supporting macro contextual factors includes: an indigenous technological capability (ITC) (that involves R \& D capacity) installed in several key industries; the existence of a well endowed and developed tertiary educational sector in selected areas; and a privately funded and controlled vocational training system that seems efficient for supplying skilled technicians to successful national firms and strategic key industries. ${ }^{8}$ While this existing capacity is limited to successful national firms in key strategic sectors, their 'model' role, especially in relation to direct suppliers and customers, is important for further diffusing NPS.

However, there are a number of constraining macro contextual factors. An important limitation perhaps, is the fact that current technological capability is limited to specific industrial sectors, so gains are distributed mainly to key strategic industries and successful national firms, leaving the majority of firms without technological support. Further, public educational and vocational training systems are lacking at primary and secondary levels. This is a factor that might severely constrain further improvements in the industrial base and, addressing it, is a long-term process. Moreover, the non-favourable general industrial relations environment is a factor that severely constrains the diffusion of NPS, as at least a minimum degree of management/worker trust is needed. The lack of a clear and stable industry policy also prevents managerial cadres from changing current organisational practices. Those macro contextual conditions assist to explain why Brazilian firms applying NPS have both taken a partial approach (Fleury and Humphrey, 1993; Posthuma, 1994) and obtained limited competitive performance indicators in spite of the significant efforts deployed by industrial firms to implement new organisational forms.

Fourth, the suggested evolutionary hybridisation of Swedish, German and Japanese production concepts that seems to be occurring at the level of the firm brings significant challenges to policy makers. The implementation and diffusion of a specific production system involves the set up of policies to build both macro and meso level institutional conditions that would eventually support firm level practices. For example while the Japanese model calls for a minimalist welfare state (in order to establish dependent relationship with workers), the European production approach calls for well endowed welfare state services; while the Japanese approach needs weak labour bargaining power (obtained through enterprise-based trade unions), the European approach calls for strong trade unions and worker

settlements, but structural variables are likely to be decisive in competition between social settlements where structural variables like wages and hours worked have different values' (p. 9).

${ }^{8}$ However, this is true only in the context of slow economic activity. If further economic activity occurs, a shortage of skilled manpower is likely to occur. 
participation in both production and distribution issues (obtained through co-determination laws); while the Japanese approach uses intensively internal labour markets, the European approach emphasises external labour markets; while the Japanese model concentrates on the mass-production of high quality and low price products (e.g., manufactured in large batches), German and Swedish production systems focused on the production of customised high quality and high performance markets (e.g., manufactured in small/medium batch size); while the Japanese model uses intensively internal training schemes, the European approach is based on the technical excellence obtained in the public sophisticated and well endowed industrial training network.

A final and key trade-off that need to be considered is the view that while the Japanese approach seems to be efficient to create resources, the European production approach seems to be adequate for both resource creation and distribution. The latter seems to be highly relevant for Brazilian path of socio-economic development since economic historian Eric Hobsbawm (1995) suggested that, unlikely the postwar period, the 1990's is an era in which the principal world problems are related more to resource distribution than to resource creation.

The above shows the complex trade-offs that are involved in the set up of an industrial policy. Then, rather than packaging together those different concepts ${ }^{9}$, it is necessary to acknowledge that they posses not only different socio-institutional preconditions but also different socio-economic outcomes.

Whilst the application of European style production systems seems to be a feasible alternative in Brazil (Meyer-Stamer, 1991; Guzman, 1998), it is necessary to admit, paraphrasing Boyer (1993), that the application of European style NPS in Brazil is an island in an Ocean of Taylorist and Fordist traditions. Pace of adoption seems to be slow as macro contextual conditions constrain rather than support its implementation. Long term economic and social outcomes are still to be seen as the application of the NPS (both Japanese and European type) seems to be in its early stages.

Thus, two safe insights can be drawn from the above. First, converging with international trends, Brazilian firms are in a period of testing alternative production models. ${ }^{10}$ Second, the dynamic evolution of production models is under way and seems to involve the adaptation of both European type production concepts and Japanese principles to Brazilian macro contextual conditions. The latter not only

\footnotetext{
${ }^{9}$ Silva (1994) for example, differentiated between traditional Fordism and post-Fordism practices. This analytical category, however, seems to be too rough for assisting to explain different management, organisation, technology and manpower practices that occurs within the post-Fordism region (Further details on the difference between Fordism, neo-Fordism and post-Fordism can be found in Badham and Mathews, 1989).

${ }^{10}$ There are two clear cases that illustrate this hypothesis. First, the Mercedes Benz plant in Juiz de Fora (MG) attempting to use a mix of German production concepts together with some Japanese techniques such as in the Rastatt plant. Second, the VW plant in Resende (RJ) is trying the "modular production" concept in order to test its feasibility.
} 
raises significant challenges to practitioners, policy makers and academics, but also provides alternative roads for industrial development.

\section{REFERENCES}

ALTMANN, N., KOHLER, C., MIEL, P. "No end in sight - current debates on the future of industrial work”, In: Altmann, N. Kohler, C., Meil, P. (eds.) Technology and Work in German Industry, London: Routledge, 1992.

ALTMANN, N., KOHLER, C., MIEL, P. “Convergence of rationalization - Divergence of interest representation”, In: Tokunaga S., Altmann N., Demes H. (E ds.) New Impacts on Industrial Relations - Internalization and changing production strategies, Munchen: Iudicium Verlag, 1992.

APPELBAUM, E., BATI, R. The New American Workplace, Ithaca: ILR Press, 1994.

AUER, P. "Lean Production: The micro-macro dimension, employment and the Welfare State", Wissenschaftszentrum discussion paper FS 194-201, Berlin, 1994.

BADHAM, R. and MATHEWS, J., “The New Production Systems Debate”, Labour \& Industry, 2(2), 1989.

BENDERS, J. "Leaving Lean? Recent Changes in the Production Organisation of some Japanese Car Planes", Economic \& Industrial Democracy, v. 17, n. 1, 1996.

BERGGREN, C. Alternatives to Lean Production, Ithaca: IRL Press, 1992.

BERGGREN, C. “Travail: du marche a l'organisation” In: DURAND, J.-P. Le Fin du Modele Suedois, Paris: Syros, 1994.

BERGGREN, C. "Japan as number two: Competitive problems and the future of alliance capitalism after the burst of the bubble boom", Work, Employment and Society, v. 9, n. 1, 1995.

BOYER, R. "Comment emerge un Nouveau Systeme Productif?” In: DURAND, J-P. Vers un Nouveau Modele Productif?, Paris: Syros, 1993.

BOWLES, S. and GINTIS, H. "Políticas igualitarias que incrementan la productividad", Revista Internacional del Trabajo, v. 114, n. 4-5, 1995.

COLE, R.E. Strategies for learning - Smal1 group activities in American, Japanese and Swedish Industry, Los Angeles: California University Press, 1990.

COOK, P., "The experiences of German engineering firms in applying lean production methods", In: SENGENBERGER, W. and CAMPBELL, D. Lean Production and Beyond - labour aspects of a new production concept, Geneva: International Institute for Labour Studies, 1993.

COUTINHO, L. "A especialização regressiva: Um balanço do desempenho industrial Pós-estabilização”, In VELLOSO, J.P. Brasil: Desafios de um país em transformação, Rio de Janeiro: Ed. José Olympo, 1997.

COUTINHO, L. and Ferraz J., Estudo da Competitividade da Industria Brasileira, Papirus/Editora da Unicamp, Campinas, 1994.

DEMES, H. "The Japanese production model as a model for the 21st Century? " In: TOKUNAGA, S., ALTAMANN, N., DEMES, H. New Impacts on Industrial Relations - Internalization and changing production strategies, Munchen: Judicium Verlag, 1992 .

DEUTSCHMANN, C. "Work Councils and Enterprise-level Industrial Relations in German Transplants of Japanese Firms", In: TOKUNAGA, S., ALTMANN, N., DEMES, H. New Impacts on Industrial Relations Internalization and changing production strategies, Munchen: Judicium Verlag, 1992.

ENDERLE, P. “The Opel Production System”, In: SHIMOKAWA, K. , et.al. Transforming Automobile Assembly - Experience in Automation and Work Organization, Berlin: Springer Verlag, 1997.

FLEURY, A. and HUMPHREY, J., "Human resources and the diffusion and adaptation of new quality methods in Brazilian manufacturing”, Institute of Development Studies, Research Report n. 24, Brighton, 1993.

FUJIMOTO, T., JURGENS, U., SHIMOKAWA, K. “Introduction”, In: SHIMOKAWA, K., JURGENS, 
U., FUJIMOTO, T. Transforming Automobile Assembly - Experience in Automation and Work Organization, Berlin: Springer Verlag, 1997.

FRITSCH, W. and FRANCO, G., Foreign Direct Investment in Brazil: Its Impact on Industrial Restructuring, OECD, 1991.

GUZMAN, G.A. New Production Systems: A comparative analysis of Swedish, German and Japanese models, DEP/UFMG Texto para Discussão, 1998.

GUZMAN, G.A. Alternative manufacturing developments from the semi-periphery: The case of Human-centred manufacturing in Brazil, unpublished Ph.D. thesis, The University of Wollongong, Australia, 1998a.

GRONNING, T. "Recent developments at Toyota Motor Co.”, In: SANDBERG, A. Enriching Production, Aldershot: Avebury, 1995.

HOBSBAWM, E. A Era dos Extremos, Rio de Janeiro: Companhia das Letras, 1995.

JURGENS, U. "Internationalization strategies of Japanese and German automobile companies", In: TOKUNAGA, S., ALTMANN, N., DEMES, H. New Impacts on Industrial Relations - Internationalization and Changing Production Strategies, Munchen: Iudicium Verlag, 1992.

JURGENS, U., MALCH, T., DOHSE, K. Breaking from taylorism, Cambridge: Cambridge University Press, 1993.

JURGENS, U. "Lean Production and Co-determination: The German Experience", paper presented at the Conference on "Lean Production and Labor: Critical and Comparative Perspectives", May 20-22, Wayne State University, 1993a.

KOYAMA, O. "Flexibilization of the Human Resource Management in Japan - Its new orientation after mid-1990s", In: GERPISA - The Fifth International Colloquium "The trajectories of Internationalization of Automobile Industry Firms”, Paris, 12-14 Juin., 1997.

KUMAZAWA, M., "Industrial Relations and Management in Japanese Companies in Europe”, In TOKUNAGA, S., ALTMANN, N. and DEMES, H. (eds.) New Impacts on Industrial Relations Internalization and changing production strategies, Iudicium Verlag, Munchen, 1992.

LUTZ, B., "The contradictions of Post-tayloristic rationalization and the uncertain future of industrial work”, In ALTMANN, N., KOHLER , C. and MEIL, P. (eds.) Technology and work in German Industry, Routledge, 1992.

MEIDNER, R., "The Swedish model in an Era of Mass Unemployment", Economic and Industrial Democracy, 18(1), 1997.

MEIDNER, R., "Essor et declin du modele suedois", In DURAND, J-P (Ed.) La fin du modele suedois?, Syros, 1994.

MEYER-STAMER, J., "New Patterns of Governance for Industrial Change: Perspectives for Brazil”, The Journal of Development Studies, 33(3), 1997.

MEYER-STAMER, J., RAUTH, C., RIAD, H., SCHMITT, S., and WELTE, T., Comprehensive Modernization on the Shop Floor: A case study on the Brazilian Machinery industry, Berlim: German Development Institute, 1991.

NEWMANN, H., "Lean production needs ‘beefing up”, In SENGENBERGER, W. and CAMPBELL, D. (eds.) Lean Production and Beyond - labour aspects of a new production concept, International Institute for Labour Studies, Geneva, 1993.

NOHARA, H., "Swedenization" in the birthplace of lean production?", In GERPISA - The International Colloquium.'The trajectories of Internationalization of Automobile Industry firms" Paris, 12-14 Juin, 1997.

NOMURA, M., "The end of Toyotism? Recent trends in Japanese automobile company", Okayama University, Department of Economics, Okayama, 1992

NOMURA, M., "Japanese Personnel Management Transferred: Transplants of the Electronic Industry in Asia and Europe", In TOKUNAGA, S. ALTMANN, N. and DEMES, H. (eds.) New Impacts on Industrial relations, Iudicium Verlag, Munchen, $1992 \mathrm{~b}$.

POSTHUMA A., "Japanese production techniques in Brazilian automobile industry: A best practice model or basis for adaptation? In ELGER, T. and SMITH, C. (eds.) Global Japanization? Routledge, 1994. 
SANDBERG, A., BROMS, G., GRIP, A., SUNDSTROM, L., STEEM, J. and ULLMARK, P., Technological Change and Co-determination in Sweden, Temple University Press, 1992.

SANDBERG, A. (ed.) Enriching Production: Perspectives on Volvo's Uddevalla Plant as an Alternative to Lean Production, Avebury, 1995.

SAUER, D., "Systemic Rationalization, Subcontracting strategies and their impact on labour in the Federal Republic of Germany”, In TOKUNAGA, S., ALTMANN, N. and DEMES, H. (eds.) New Impacts on Industrial Relations - Internalization and changing production strategies, Iudicium Verlag, Munchen, 1992.

SILVA, E., “Pós-fordismo no Brasil”, Revista de Economia Política, 14 (3), 1994.

SHIMIZU, K., " Humanization of the production system and work at Toyota Motor Co. and Toyota Motor Kyushu”, In SANDBERG, A. (Ed.) Enriching Production, Avebury, Aldershot, 1995.

SHIMOKAWA, K., JURGENS, U., and FUJIMOTO, T. (eds.) Transforming Automobile Assembly - Experience in Automation and Work Organization, Springer, Berlin, 1997.

SUZIGAN W., "Experiência histórica de política industrial no Brasil”, Revista de Economia Política, 16(1), 1996.

TAUILLE J. R., “Flexibilidade dinâmica, cooperação e eficiência econômica: anotações”, Revista de Economia Política, 14 (1), 1994.

TURNER L. and AUER, P., "The political economy of new work organisation - Different roads, different outcomes", Wissenschaftszentrum discussion paper FSI 92-4, Berlin, 1992.

WILLIAMS K., H ASLAM, C., JOHAL, S., WILLIAMS, J., ADCROFT, A. and WILLIS, R., "Management Practice or Structural Factors: The case of America versus Japan in the car industry", Economic and Industrial Democracy, 16(1), 1995. 